\title{
Coxsackie Virus Induced Graves' Disease in an Immunocompetent Patient
}

\author{
Wesley Tang, DO, MPH; Sulagna Das, MD; Zoltán Krudy, MD \\ Department of Medicine, Kettering Medical Center, Kettering, OH, USA \\ *Corresponding Author: Wesley Tang, DO, MPH; wesley.tang @ ketteringhealth.org
}

Received 12 September 2021;

Accepted 27 September 2021;

Published 10 October 2021

\begin{abstract}
Enteroviruses, such as Coxsackie virus, have been implicated in the past as a pathogen associated with subacute thyroiditis, also known as de Quervain's thyroiditis. Less commonly are viruses associated with autoimmune thyroid diseases such as Hashimoto's thyroiditis and Graves' disease. We present a case of a healthy 43 year old female who presented to the emergency department complaining of several months of weakness, nausea, loose bowel movements, anxiousness, and shortness of breath. Physical exam revealed tachycardia, tremors, and a non-tender thyroid gland to palpation. Skin exam showed a rash on the palms of her hands and soles of her feet bilaterally with dark papules, suggestive of Hand, foot, and mouth disease. Laboratory workup would reveal an undetectable thyroid stimulating hormone (TSH), and levels of T3 \& T4 too high to quantify. Thyroid receptor antibodies would return as positive, diagnostic of Graves' disease. Coxsackie virus (the causative agent of Hand, foot, and mouth disease) IgM titers also returned positive suggesting recent infection. Although the etiology of Graves' disease is still not clear, this case report provides evidence that environmental triggers such as Coxsackie viral infection may be involved in its pathogenesis.
\end{abstract}

Keywords: Graves' disease, hyperthyroidism, thyroiditis, Coxsackie virus, infectious diseases

\section{Introduction}

Autoimmune diseases are hypothesized to be caused by a combination of infection, genetic, and environmental factors. One example of an autoimmune disease is Graves' disease, a disorder that affects the thyroid gland and is the most common cause of hyperthyroidism in the United States ${ }^{[1]}$. Graves' disease can present with hyperactivity, tachycardia, fever, hyper-reflexia, muscle weakness, tremors, weight loss, and increased appetite ${ }^{[2]}$. The disease is caused by the appearance of stimulating thyroid stimulating hormone (TSH) receptor autoantibodies that leads to the syndrome of hyperthyroidism ${ }^{[3]}$. Separately, viral infections are frequently implicated as a major factor in autoimmune diseases ${ }^{[4]}$. Case reports detailing evidence of infection with HTLV1, HIV, adenovirus, parvovirus, HHV6, HFV, and SV40 have been implicated as a precursor to Graves' disease. Regarding Coxsackie virus, an Enterovirus, it is most often associated with subacute thyroiditis (also known as de Quervain's thyroiditis), and not in autoimmune thyroid diseases. Coxsackie virus is the causative agent of Hand, foot, and mouth disease (HFMD), a disorder that typically presents as a self-limited illness characterized by oral ulcerations, and vesicular rashes on the palms, soles, and/or buttocks ${ }^{[5]}$. Here, we present a case of Graves' disease likely triggered by Coxsackie virus infection.

\section{Case Description}

A 43-year-old female presented to the emergency department complaining of generalized weakness, nausea, and vomiting. She stated that her symptoms had been progressing over the past several months. Prior to arrival, she had not sought care with her primary care physician. She stated that no matter what she did, her nausea and vomiting was persistent daily. She did not endorse any abdominal pain but did endorse loose bowel movements. The patient also noticed that she had swelling in the front of her neck over the same period of time and occasionally felt tightness in her neck. She denied trouble swallowing or choking. She additionally endorsed feeling tremulous and anxious but denied chest pain and shortness of breath. Past medical history was significant for cholecystectomy, sexually transmitted infections (unspecified), and obesity. Social history revealed that she was a nurse, and frequently traveled domestically in the United States.

Physical exam revealed a well-nourished, well-developed female of stated age who appeared anxious but in no acute distress. She was tachycardic with normal heart sounds and regular rhythm. Breath sounds were equal to auscultation bilaterally. Abdomen was soft, nontender, nondistended, without rebound, or guarding. The anterior neck was full to palpation, and not tender to palpation. The patient was tremulous at rest. She was neurologically intact, alert \& oriented, and without focal neurological deficits. Integument exam 
showed a rash on the palms of her hands and soles of her feet bilaterally with dark round plaques (Figure 1).

Laboratory workup demonstrated a TSH that was undetectable, and her T3 \& T4 too high to quantify. A thyroid/neck ultrasound showed mild heterogeneous appearance of the thyroid gland with hypervascularity and without nodules, negative thyroperoxidase antibodies, and thyroid receptor antibodies positive, suggestive of Graves' disease. A nuclear medicine thyroid uptake scan was obtained which revealed an enlarged thyroid gland with diffuse uniform uptake of the radiotracer (Figure 2). The decision was made to start the patient on oral propranolol $60 \mathrm{mg}$ twice daily, and was later started on methimazole at time of discharge. HIV, ANA, urine hCG, hepatitis A, hepatitis B, hepatitis $\mathrm{C}$, and syphilis testing returned negative. Coxsackie A7, A9, A16, and A24 returned negative. Coxsackie B2, B3, B4, B6 returned negative. Coxsackie $\mathrm{B} 1 \mathrm{AB}$ returned positive at titers $1: 8$, and
Coxsackie $\mathrm{B} 5 \mathrm{AB}$ returned positive at titers 1:32. According to the reference laboratory, titers greater than or equal to $1: 32$ are indicative of recent infection, whereas titers of $1: 8$ may be indicative of either past or recent.

A thyroid ultrasound was performed that demonstrated a mild heterogenous appearance of the thyroid gland with hypervascularity, and without discrete nodules. A nuclear medicine iodine 131 uptake scan was performed, demonstrating a diffusely enlarged thyroid with uniform uptake of the radiotracer, consistent with Graves' disease. She had considerable improvement in her symptoms with the initiation of propranolol, and methimazole. By time of hospital discharge, the patient was not found to be in any acute distress, with vital signs within normal limits, and no new abnormalities on physical examination. She continues to follow up with her endocrinologist on an outpatient basis.

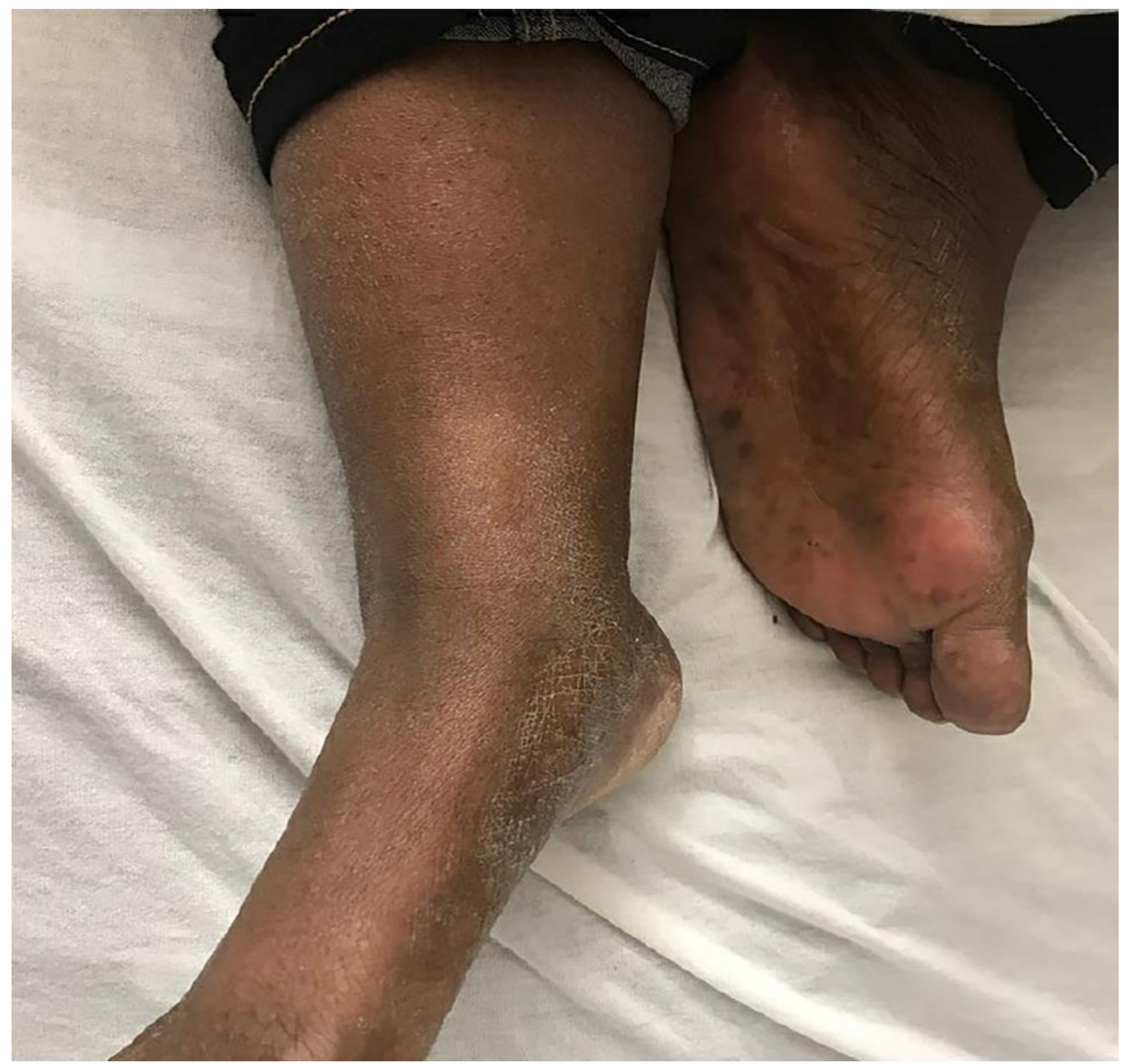

Figure 1: Papules and lesions on the soles of the feet characteristic of Hand, foot, and mouth disease 


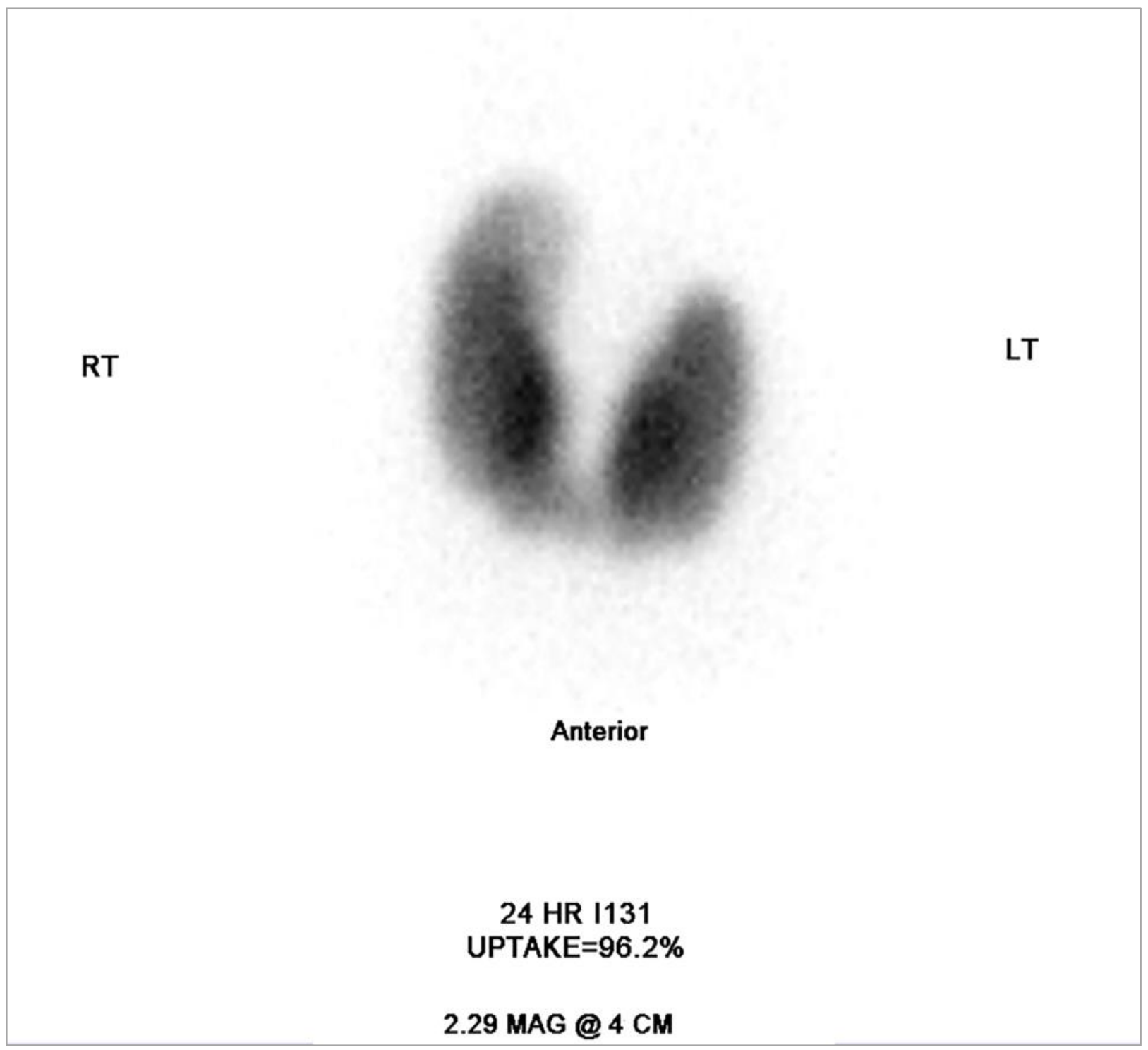

Figure 2: Nuclear medicine I 131 thyroid uptake scan showing diffuse uptake consistent with Graves' disease

\section{Discussion}

In summary, our patient is a 43-year-old immunocompetent patient who developed Graves' disease, following an episode of Coxsackie virus induced Hand, foot, and mouth disease. Treatment of Graves' disease include medications (eg. propylthiouracil, methimazole), radioiodine, and surgical resection. No treatment modality has demonstrated superiority, though considerations such as pregnancy and experience of the surgeon should be considered before choosing ${ }^{[6]}$. In this case, methimazole was chosen as the treatment of choice.

A PubMed search from 1950 to the present using the terms 'Coxsackie virus', 'hand, foot, mouth disease', 'enterovirus', 'Graves' disease', 'thyrotoxicosis', and 'hyperthyroidism' was performed and found limited literature, and no case reports.

Kraemer and colleagues explored the possibility of a connection between Coxsackie B virus infection and Graves' disease ${ }^{[7]}$. They determined that Graves' disease is associated with the human leukocyte antigen HLA-DR3. They further demonstrated a significant association between HLA-DR3 antigen and lymphocytotoxic antibodies, ie IgG antibodies from Graves' disease patients that were cytotoxic to normal B cells. Following infection with Coxsackie $\mathrm{B}$ virus, lymphocytotoxic reactions against HLA-DR3+ B cells were completely inhibited. This study strongly suggested a mechanism for which Coxsackie virus reactive HLA-DR3 antibodies may contribute to the pathogenesis of Graves' disease.

Desailloud and colleagues on the other hand sought to determine whether Enterovirus genome sequences could be isolated in postoperative thyroid tissue from patients with Graves' disease $^{[8]}$. Of 86 studied tissue samples, 22 samples demonstrated RNA specific for Enterovirus.

Cui and colleagues described a case in which a 46 year old woman with acute hepatitis B infection who presented with Graves' disease ${ }^{[9]}$. She was noted to have improved thyroid function with the treatment and clearance of hepatitis B viral DNA, and concluded that the Graves' disease was likely an extrahepatic manifestation of acute hepatitis B virus infection.

In conclusion, there is likely an association between Coxsackie viral infection, and Graves' disease, an autoimmune disorder. Although there is some serological evidence to suggest a connection between Enteroviruses and/or Coxsackie viruses and Graves' disease, there are not yet clinical case reports to strengthen this association. This case aims to fill that gap. However, more extensive research is needed to establish the link between Coxsackie viruses and Graves' disease.

\section{Funding Support}

None 


\section{Conflicts of Interest Statement}

The authors declare that they do not have a conflict of interest

\section{Author Contributions Statement}

WT, SD, \& ZK designed and conducted the research. ZK provided the data. WT had primary responsibility for final content. All authors read and approved the final manuscript

\section{References}

[1] De Leo, S., S.Y. Lee, and L.E. Braverman, Hyperthyroidism. Lancet, 2016. 388(10047): p. 906-918.

[2] Shukla, S.K., et al., Infections, genetic and environmental factors in pathogenesis of autoimmune thyroid diseases. Microb Pathog, 2018. 116: p. 279-288.

[3] Desailloud, R. and D. Hober, Viruses and thyroiditis: an update. Virol J, 2009. 6: p. 5.

[4] Prummel, M.F., T. Strieder, and W.M. Wiersinga, The environment and autoimmune thyroid diseases. Eur $\mathrm{J}$ Endocrinol, 2004. 150(5): p. 605-18.

[5] Mirand, A., et al., Outbreak of hand, foot and mouth disease/herpangina associated with coxsackievirus A6 and A10 infections in 2010, France: a large citywide, prospective observational study. Clin Microbiol Infect, 2012. 18(5): p. E110-8.

[6] Corvilain, B., et al., Treatment of adult Graves' disease. Ann Endocrinol (Paris), 2018. 79(6): p. 618-635.

[7] Kraemer, M.H., et al., Relationship between HLA antigens and infectious agents in contributing towards the development of Graves' disease. Immunol Invest, 1998. 27(1-2): p. 17-29.

[8] Desailloud, R., et al., Detection of enterovirus RNA in postoperative thyroid tissue specimens. Clin Endocrinol (Oxf), 2009. 70(2): p. 331-4.

[9] Cui, W., et al., Graves' hyperthyroidism accompanied with acute hepatitis B virus infection: an extrahepatic manifestation? Virol J, 2016. 13: p. 80.

\begin{abstract}
cC (7) Open Access This article is licensed under a Creative Commons Attribution 4.0 International License, which permits use, sharing, adaptation, distribution and reproduction in any medium or format, as long as you give appropriate credit to the original author(s) and the source, provide a link to the Creative Commons license, and indicate if changes were made. The images or other third party material in this article are included in the article's Creative Commons license, unless indicated otherwise in a credit line to the material. If material is not included in the article's Creative Commons license and your intended use is not permitted by statutory regulation or exceeds the permitted use, you will need to obtain permission directly from the copyright holder. To view a copy of this license, visit https://creativecommons.org/licenses/by/4.0/.
\end{abstract}

(C) The Author(s) 2021 